\title{
Analysis of Variance of the Diode Parameters in Multiband Rectifiers for RF Energy Harvesting
}

\author{
Andry CONTRERAS ${ }^{1}$, Maryory URDANETA $^{2}$ \\ ${ }^{1}$ Dept. of Circuits and Communications, Universidad del Zulia, Maracaibo, Venezuela \\ ${ }^{2}$ Dept. of Mathematics, Universidad Tecnologica Israel, Quito, Ecuador \\ acontreras@fing.luz.edu.ve, murdaneta@uisrael.edu.ec \\ Submitted August 15, 2020 / Accepted January 15, 2021
}

\begin{abstract}
The aim of this work was the characterization of the diode parameters from the single diode and voltage doubler rectifiers employed in multiband rectennas. For that, an analysis of variance was made through the $2^{k}$ factorial design for determining the effects on the RF-DC conversion efficiency, with basis on the diode families that have been used in this type of rectennas. For both types of rectifiers the most influential parameters were the junction capacitance and the saturation current. The results in the trends of the parameter levels showed that the diode must have a high level of saturation current and a low level of junction capacitance, mainly. Additionally, these must have a low level of series resistance and emission coefficient. There were no interactions of the parameters for each evaluated load resistance. Among the diode families employed in literature, there was no particular family that complies with these criteria. Therefore, the selection of the diode family must be made through a trade-off between the parameters, which is accomplished by the family SMS-763x.
\end{abstract}

\section{Keywords}

Diode parameters, multiband rectifier, ANOVA, RF energy harvesting

\section{Introduction}

In recent years, the radio frequency $(\mathrm{RF})$ energy harvesting systems have had an important development because the RF signals from different communication systems are ubiquitous. One of the most promising devices for the harvesting of these signals is the rectenna or rectifying-antenna, which can convert the energy necessary for supplying low-consumption devices, for example, sensors and watches [1-3].

The rectennas have low incident power levels, thus their RF-DC conversion efficiency must be high to avoid losses and take advantage of all the available energy [4]. This efficiency depends on the rectifier circuits used and the nonlinear components selected [3]. The rectifiers have been designed for different bands of the communication systems, such as the Global System for Mobile Communications (GSM), Universal Mobile Telecommunications System (UMTS), Long Term Evolution (LTE), Wireless Local Access Network (WLAN), and Interoperability for Microwave Access (Wi-Max) [1,5]. These can be rectifiers of a single band or multiband, the former collects energy from a single frequency band in an ambient environment, while the latter one converts energy from different frequency bands simultaneously [2].

The rectifiers in RF employ nonlinear elements as diodes, which in general are of the Schottky type because they fulfill the requirements of the RF circuits [5]. In the design of rectennas, different diode families have been employed in recent years, being the HSMS-28xy and SMS-7630 the most widely used $[1,2,5]$. In most of the cases, the selection of the diode family depended on the availability or the preference of the authors, showing no particular selection criteria. However, some research works carried out this selection through the comparison of the rectifier performance with diverse commercial diodes, both for a single band rectifier [6] and a multiband rectifier [7]. After the rigorous analysis of literature, it has been detected that there are no established selection criteria that allow to decide on a diode or a diode family with basis on their fundamental characteristics, and how they influence the performance of the rectifier.

In this sense, this work aims to determine a set of selection criteria for diodes that permits to obtain the best conversion efficiency for the rectifiers of multiband rectennas for frequencies between $1.7 \mathrm{GHz}$ and $3.7 \mathrm{GHz}$. This is accomplished through the characterization of the diode parameters on the rectifiers, in terms of their effects in the RF-DC conversion efficiency through the analysis of variance (ANOVA), with basis on the diode families used in multiband rectennas.

\section{Parameters of the Diodes Employed in Rectifiers for Rectennas}

In this research, two types of rectifiers were considered, a single diode and a voltage doubler, because these have been the most commonly used in recent years [1]. The first one is 
a rectifier of half-wave (Fig. 1(a)), whose diode D conducts only in the positive half of the wave that charges the capacitor $\mathrm{C}$, and it keeps the voltage during the negative half-wave. The second one is a full-wave rectifier (Fig. 1(b)) that conducts through the diode D1 during the positive half of the wave and the series capacitor $\mathrm{C} 1$ charges the capacitor $\mathrm{C} 2$. While in the negative half of the wave, $\mathrm{C} 1$ is charged for helping $\mathrm{C} 2$ in the other half wave, through D2 that conducts in the same way that D1 [8].

The fundamental parameters of the Schottky diode are the emission coefficient $(N)$, the series resistance $\left(R_{\mathrm{S}}\right)$, the junction capacitance $\left(C_{\mathrm{J}}\right)$, and the saturation current $\left(I_{\mathrm{S}}\right)$. The emission coefficient is a constant and it cannot model the change in the I-V characteristic curve, for convergence its value must be higher than 0.01 . The series resistance is a constant and it does not depend on the current, the voltage, or the temperature. The junction capacitance is an approximation of the real capacitance of the diode, especially in the reverse bias region. The saturation current is a constant that does not depend on the reverse bias voltage, thus the reverse leakage current is kept constant in the reverse bias region until the rupture voltage [8].

For the simulation of microwave electronic circuits with basis on SPICE, AWR software was used, where the model of the Schottky diode is shown in Fig. 2. Its current is calculated by:

$$
I=I_{\mathrm{S}}\left(\mathrm{e}^{\frac{q V}{N K T}}-1\right)
$$

where $q V$ is the charge of the electron, $K$ is the Boltzmann constant, and $T$ is the temperature. Using the AWR software, the variation of the RF-DC conversion efficiency is determined in terms of the values of the Schottky diode parameters. In this way, the effects of such parameters over the RF-DC conversion efficiency can be evaluated. In the rectifiers previously designed in literature, different types of diode families have been used for applications of two bands or more, corresponding to the mobile telephony and WLAN. These families are: HSMS-282x [9-11]; HSMS285x [12-17]; HSMS-286x [18, 19]; SMS-762x [20]; and SMS-763x [21-26].

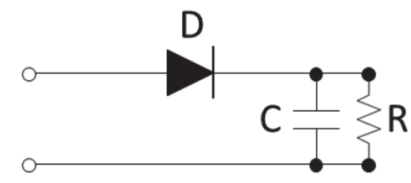

(a)

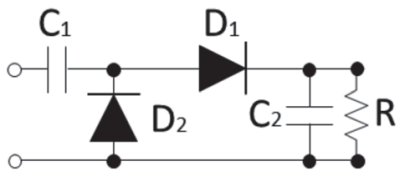

(b)
Fig. 1. Rectifier with a single diode (a) and voltage doubler (b).

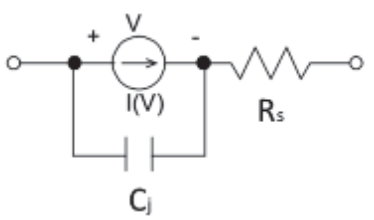

Fig. 2. Equivalent model of the Schottky diode in SPICE.

\begin{tabular}{|c|c|c|c|c|}
\hline Family & $N$ & $R_{\mathbf{S}}[\Omega]$ & $C_{\mathbf{j}}[\mathrm{pF}]$ & $I_{\mathbf{S}}[\mathrm{A}]$ \\
\hline HSMS-282x [27] & 1.08 & 6 & 0.70 & $2.2 \times 10^{-8}$ \\
\hline HSMS-285x [28] & 1.06 & 25 & 0.18 & $3.0 \times 10^{-6}$ \\
\hline HSMS-286x [29] & 1.08 & 6 & 0.18 & $5.0 \times 10^{-8}$ \\
\hline SMS-762x [30] & 1.05 & 12 & 0.10 & $4.0 \times 10^{-8}$ \\
\hline SMS-763x [30] & 1.05 & 20 & 0.14 & $5.0 \times 10^{-6}$ \\
\hline
\end{tabular}

Tab. 1. Parameters of the SPICE model from the commercial diodes used in the rectennas.

The parameters of these diode families are shown in Tab. 1, where the range of operative frequency of the diode is also indicated.

\section{The $2^{k}$ Factorial Design}

An ANOVA with $2^{k}$ factorial design with 4 factors for each type of rectifier was applied through the statistical software StatgraphicsCenturion XVI, considering a level of significance of 0.05 . With this method, fewer evaluations of the dependent variable using simulation are needed for determining the influence of the factors, which are the Schottky diode parameters. Additionally, this method is widely used for the selection of significant variables in an experiment [31]. The range of each parameter is shown in Tab. 2. These ranges were selected considering the values of commercial Schottky diode parameters employed in the rectennas designed in recent years. The simulation of the multiband rectifiers was done in a range from 1.7 to $3.7 \mathrm{GHz}$ for the operation frequency and the input power of the rectifier was between -40 and $0 \mathrm{dBm}$. In the selected frequency range various communication systems can be harvested, such as the WLAN system at $2.45 \mathrm{GHz}$, and the mobile telephony systems GSM, UMTS, LTE, and 5G [32]. The multiband rectifiers permit to maximize the RF-DC conversion efficiency [33]. The simulation allows to evaluate of the power output of the rectifier for different frequency components and diode parameters. This is employed to calculate the mean of the RF-DC conversion efficiency for different input power levels and operation frequency bands through:

$$
\bar{\eta}_{\mathrm{RF}-\mathrm{DC}}=\frac{100}{m n} \sum_{j=1}^{m} \sum_{i=1}^{n} \frac{P_{\mathrm{DC}}(i, j)}{P_{\mathrm{in}}(j)}[\%]
$$

where $P_{\mathrm{DC}}$ is the effective value of the harvested power, $P_{\text {in }}$ is the input power, $m$ is the number of the levels from the input power $j$, and $n$ is the number of the frequency components $i$. With these results, the influence of each parameter was evaluated for the rectifier of a single diode and the voltage doubler. This allows to establish the characteristics of the diode for obtaining the best performance in terms of the conversion efficiency.

\begin{tabular}{|c|c|c|}
\hline Parameter & Low Level $[-1]$ & High Level $[+1]$ \\
\hline$N$ & 1.0 & 1.1 \\
\hline$R_{\mathbf{S}}[\Omega]$ & 5 & 25 \\
\hline$C_{\mathbf{j}}[\mathrm{pF}]$ & 0.1 & 0.9 \\
\hline$I_{\mathbf{S}}[\mathrm{A}]$ & $10^{-8}$ & $10^{-5}$ \\
\hline
\end{tabular}

Tab. 2. Ranges for the design parameter of the diode. 


\section{Analysis of Diodes in the Single Diode Rectifier}

The rectifier with a single diode was simulated for all the values of diode parameters, and the results of mean RF-DC conversion efficiency are shown in Tab. 3 for three different values of load resistance $(R)$. The selected values of resistance were 100,500 , and $1000 \Omega$ for evaluating the one that improves the performance of the rectifiers. Consequently, 16 runs were made for each value of load resistance to determine the influence of the 4 factors (parameters), according to the low and high levels previously established in Tab. 2.

The results of the ANOVA for the rectifier with a single diode are shown in Tab. 4 for load resistances $100 \Omega$, $500 \Omega$, and $1000 \Omega$. It is noted that the factors saturation current, junction capacitance, and series resistance were significant for the performance of conversion efficiency, while the emission coefficient did not reach statistical significance because its P-value was higher than 0.21 , which is considerably above the level of significance (0.05) of the test [31]. This behavior happened in the single diode rectifier for all the load resistances evaluated.

Concerning the influence of the main effects in this rectifier, the high level of saturation current was more important than the rest of the effects for increasing the RF-DC conversion efficiency. In contrast, the other main effects must have a low level to increase the efficiency. This behavior is evidenced in Fig. 3 that shows the standardized Pareto diagram of the effects over efficiency for the three values of load resistance, where the gray color indicates a high level, and the blue color represents a low level of the corresponding parameter. In Fig. 4 the influence of the main effects for the different values of load resistance is shown, where it was determined that the values near $100 \Omega$ permit obtaining a higher conversion efficiency, considering the contribution of the aforementioned parameters.

\begin{tabular}{|c|c|c|c|c|c|c|c|}
\hline \multirow{2}{*}{$\mathbf{N}^{o}$} & \multirow{2}{*}{$N$} & \multirow{2}{*}{$R_{\mathbf{S}}$} & $C_{\mathbf{j}}$ & $I_{\mathbf{S}}$ & \multicolumn{3}{|c|}{$R[\Omega]$} \\
\hline & & & & & $\mathbf{1 0 0}$ & $\mathbf{5 0 0}$ & $\mathbf{1 0 0 0}$ \\
\hline 0 & -1 & -1 & -1 & -1 & 3.86 & 3.61 & 2.65 \\
\hline 1 & -1 & -1 & -1 & +1 & 8.46 & 7.90 & 5.94 \\
\hline 2 & -1 & -1 & +1 & -1 & 2.38 & 2.03 & 1.46 \\
\hline 3 & -1 & -1 & +1 & +1 & 5.65 & 4.89 & 3.57 \\
\hline 4 & -1 & +1 & -1 & -1 & 2.62 & 2.95 & 2.32 \\
\hline 5 & -1 & +1 & -1 & +1 & 5.87 & 6.57 & 5.25 \\
\hline 6 & -1 & +1 & +1 & -1 & 1.21 & 1.20 & 0.90 \\
\hline 7 & -1 & +1 & +1 & +1 & 3.13 & 3.15 & 2.39 \\
\hline 8 & +1 & -1 & -1 & -1 & 3.42 & 3.24 & 2.39 \\
\hline 9 & +1 & -1 & -1 & +1 & 7.83 & 7.38 & 5.56 \\
\hline 10 & +1 & -1 & +1 & -1 & 2.08 & 1.79 & 1.29 \\
\hline 11 & +1 & -1 & +1 & +1 & 5.20 & 4.53 & 3.32 \\
\hline 12 & +1 & +1 & -1 & -1 & 2.33 & 2.65 & 2.09 \\
\hline 13 & +1 & +1 & -1 & +1 & 5.44 & 6.13 & 4.92 \\
\hline 14 & +1 & +1 & +1 & -1 & 1.05 & 1.05 & 0.79 \\
\hline 15 & +1 & +1 & +1 & +1 & 2.87 & 2.90 & 2.21 \\
\hline
\end{tabular}

Tab. 3. Mean RF-DC efficiency $2^{4}$ factorial design of experiment for the rectifier with a single diode.

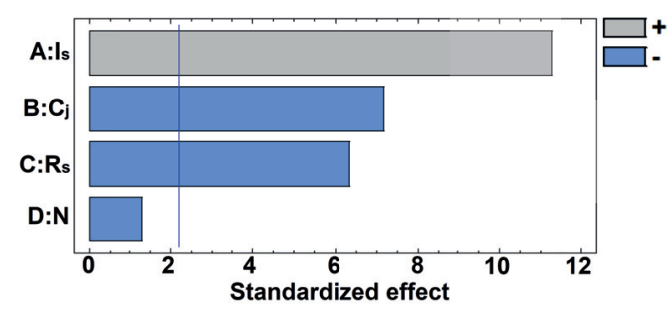

(a)

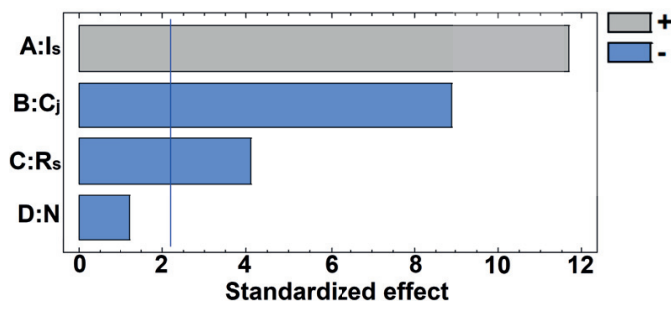

(b)

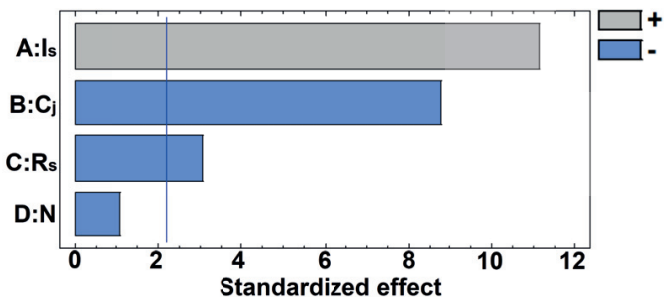

(c)

Fig. 3. Diagram of standardized Pareto for the efficiency of the rectifier with a single diode, when the load resistance was $100 \Omega$ (a), $500 \Omega$ (b), and $1000 \Omega$ (c).

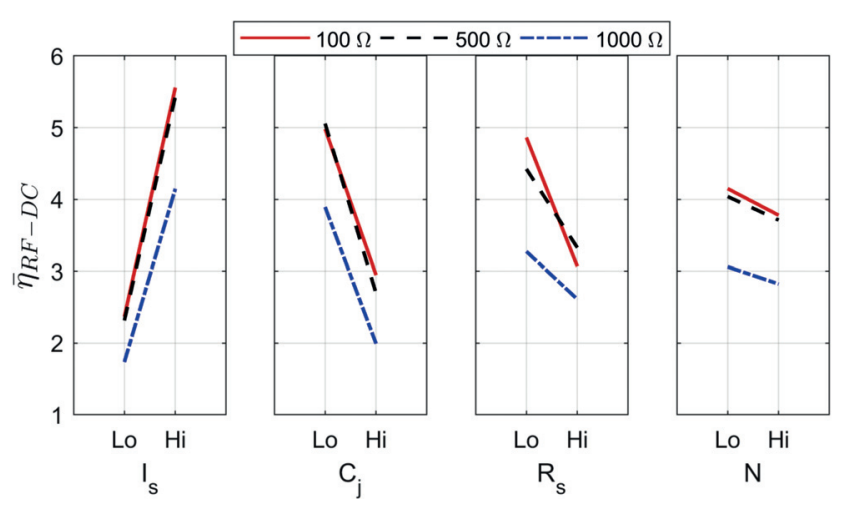

Fig. 4. Influence of the main effects in the conversion efficiency of the rectifier with a single diode.

Regarding the interactions of the effects, there were no interactions between the main effects, as is shown in Fig. 5, because the lines of the effects do not cross, i.e. the results from the low level do not intercept with the results from the high level, presenting the same behavior, ascending or descending.

\section{Analysis of the Diodes in Voltage Doubler}

To determine the influence of the diode parameters in the voltage doubler rectifier, it was considered that the two 


\begin{tabular}{|c|c|c|c|c|c|c|}
\hline Case & Source & Sum of squares & Degrees of freedom & Mean square & F value & P-value \\
\hline \multirow{5}{*}{$R=100 \Omega$} & $\mathrm{A}: I_{\mathrm{S}}$ & 40.6406 & 1 & 40.6406 & 125.90 & 0.0000 \\
\cline { 2 - 7 } & $\mathrm{B}: C_{\mathrm{j}}$ & 16.5242 & 1 & 16.5242 & 51.19 & 0.0000 \\
\cline { 2 - 7 } & $\mathrm{C}: R_{\mathrm{S}}$ & 12.8881 & 1 & 12.8881 & 39.92 & 0.0001 \\
\cline { 2 - 7 } & $\mathrm{D}: N$ & 0.5476 & 1 & 0.5476 & 1.70 & 0.2194 \\
\cline { 2 - 7 } & Error total & 3.55095 & 11 & 0.322814 & - & - \\
\cline { 2 - 7 } & Total(corr.) & 74.1515 & 15 & - & - & - \\
\hline \multirow{5}{*}{$R=500 \Omega$} & $\mathrm{A}: I_{\mathrm{S}}$ & 38.8441 & 1 & 38.8441 & 137.79 & 0.0000 \\
\cline { 2 - 7 } & $\mathrm{B}: C_{\mathrm{j}}$ & 22.302 & 1 & 22.302 & 79.11 & 0.0000 \\
\cline { 2 - 7 } & $\mathrm{C}: R_{\mathrm{S}}$ & 4.80706 & 1 & 4.80706 & 17.05 & 0.0017 \\
\cline { 2 - 7 } & $\mathrm{D}: N$ & 0.432306 & 1 & 0.432306 & 1.53 & 0.2414 \\
\cline { 2 - 7 } & Error total & 3.10092 & 11 & 0.281902 & - & - \\
\cline { 2 - 7 } & Total(corr.) & 69.4863 & 15 & - & - & - \\
\hline \multirow{5}{*}{$R=1000 \Omega$} & $\mathrm{A}: I_{\mathrm{S}}$ & 23.2083 & 1 & 23.2083 & 123.42 & 0.0000 \\
\cline { 2 - 7 } & $\mathrm{B}: C_{\mathrm{j}}$ & 14.421 & 1 & 14.421 & 79.11 & 0.0000 \\
\cline { 2 - 7 } & $\mathrm{C}: R_{\mathrm{S}}$ & 1.76226 & 1 & 1.76226 & 9.37 & 0.0108 \\
\cline { 2 - 7 } & $\mathrm{D}: N$ & 0.228006 & 1 & 0.228006 & 1.21 & 0.2944 \\
\cline { 2 - 7 } & Error total & 2.06852 & 11 & - & - & - \\
\cline { 2 - 7 } & Total(corr.) & 41.6881 & 15 & & - \\
\hline
\end{tabular}

Tab. 4. ANOVA of the rectifier with a single diode.

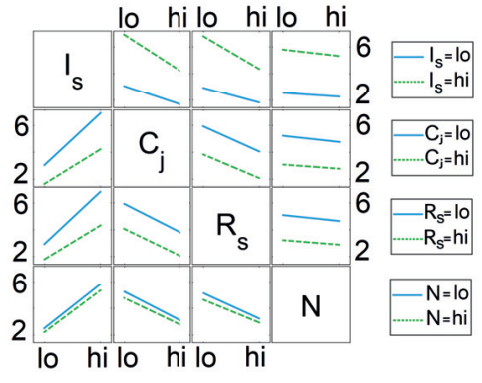

(a)

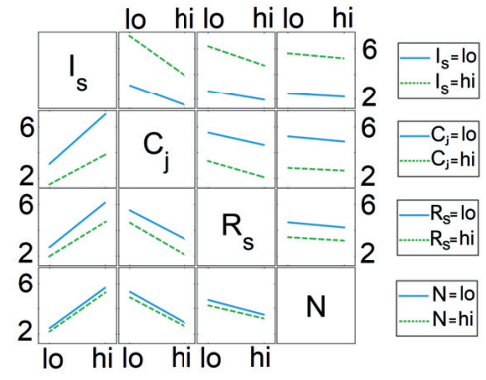

(b)

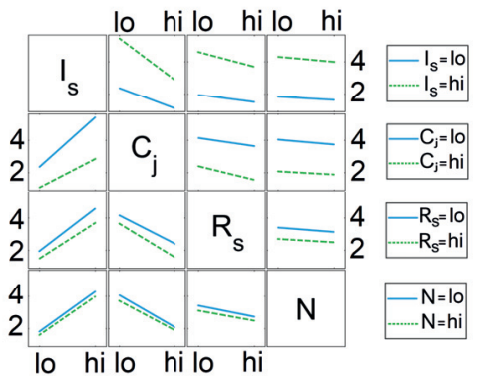

(c)

Fig. 5. Influence of the interaction between the main effects in the conversion efficiency of the rectifier with a single diode, when the load resistance was $100 \Omega(\mathrm{a}), 500 \Omega(\mathrm{b})$, and $1000 \Omega$ (c).

diodes in the rectifier had the same characteristics. Table 5 is shown the results of the mean RF-DC conversion efficiency for the different values of load resistance. In the same way that it was done for the single diode rectifier, 16 runs were made to determine the influence of the 4 factors, according to the low and high levels previously established in Tab. 2.

The statistical behavior obtained for the voltage doubler rectifier, was similar to the rectifier with a single diode in terms of the influence of their parameters in the maximization of the conversion efficiency, where the saturation current, junction capacitance, and series resistance were the significant factors, while the emission coefficient had no statistical significance. Additionally, when load resistance incremented the main effect of the series resistance was less significant, so this effect was not significant for a load resistance of $1000 \Omega$, because it had a P-value higher than the level of significance (Tab. 6). The most dominant main effect was the junction capacitance, followed by the saturation current and the series resistance. Regarding the trend of the levels of the parameters, the behavior obtained was similar to the rectifier with a single diode, as it is shown in Fig. 7, higher efficiency levels are obtained with a high level of $I_{S}$ and low levels of the rest of parameters. The influence of the main effects is shown in Fig. 8, where values near $500 \Omega$ permit to improve the performance of the rectifier.

\begin{tabular}{|c|c|c|c|c|c|c|c|}
\hline \multirow{2}{*}{$\mathbf{N}^{o}$} & \multirow{2}{*}{$N$} & \multirow{2}{*}{$R_{\mathbf{S}}$} & $C_{\mathbf{j}}$ & $I_{\mathbf{S}}$ & \multicolumn{3}{|c|}{$R[\Omega]$} \\
\cline { 5 - 8 } & & & & $\mathbf{1 0 0}$ & $\mathbf{5 0 0}$ & $\mathbf{1 0 0 0}$ \\
\hline 0 & -1 & -1 & -1 & -1 & 5.81 & 8.15 & 7.05 \\
\hline 1 & -1 & -1 & -1 & +1 & 12.79 & 17.74 & 15.43 \\
\hline 2 & -1 & -1 & +1 & -1 & 2.05 & 2.17 & 1.65 \\
\hline 3 & -1 & -1 & +1 & +1 & 6.01 & 6.28 & 4.80 \\
\hline 4 & -1 & +1 & -1 & -1 & 3.63 & 6.12 & 5.72 \\
\hline 5 & -1 & +1 & -1 & +1 & 8.17 & 13.64 & 12.75 \\
\hline 6 & -1 & +1 & +1 & -1 & 0.89 & 1.15 & 0.94 \\
\hline 7 & -1 & +1 & +1 & +1 & 2.96 & 3.74 & 3.07 \\
\hline 8 & +1 & -1 & -1 & -1 & 5.12 & 7.28 & 6.32 \\
\hline 9 & +1 & -1 & -1 & +1 & 11.82 & 16.51 & 14.40 \\
\hline 10 & +1 & -1 & +1 & -1 & 1.71 & 1.84 & 1.41 \\
\hline 11 & +1 & -1 & +1 & +1 & 5.43 & 5.72 & 4.39 \\
\hline 12 & +1 & +1 & -1 & -1 & 3.21 & 5.47 & 5.13 \\
\hline 13 & +1 & +1 & -1 & +1 & 7.55 & 12.70 & 11.91 \\
\hline 14 & +1 & +1 & +1 & -1 & 0.73 & 0.96 & 0.79 \\
\hline 15 & +1 & +1 & +1 & +1 & 2.66 & 3.39 & 2.80 \\
\hline
\end{tabular}

Tab. 5. Mean RF-DC efficiency $2^{4}$ factorial design of experiment for the rectifier of the voltage doubler. 


\begin{tabular}{|c|c|c|c|c|c|c|}
\hline Case & Source & Sum of squares & Degrees of freedom & Mean square & F value & P-value \\
\hline \multirow{6}{*}{$R=100 \Omega$} & $\mathrm{A}: I_{\mathrm{S}}$ & 73.2736 & 1 & 73.2736 & 58.50 & 0.0000 \\
\hline & $\bar{B}: C_{j}$ & 79.4772 & 1 & 79.4772 & 63.45 & 0.0000 \\
\hline & $\mathrm{C}: R_{\mathrm{S}}$ & 27.4052 & 1 & 27.4052 & 21.88 & 0.0007 \\
\hline & $\mathrm{D}: N$ & 1.0404 & 1 & 1.0404 & 0.83 & 0.3816 \\
\hline & Error total & 13.7785 & 11 & 1.25259 & - & - \\
\hline & Total(corr.) & 194.975 & 15 & - & - & - \\
\hline \multirow{6}{*}{$R=500 \Omega$} & $\mathrm{A}: I_{\mathrm{S}}$ & 135.606 & $\overline{1}$ & 135.606 & 47.23 & 0.0000 \\
\hline & $\overline{\mathrm{B}: C_{\mathrm{j}}}$ & 243.048 & 1 & 243.048 & 84.65 & 0.0000 \\
\hline & $\mathrm{C}: R_{\mathrm{S}}$ & 21.4369 & 1 & 21.4369 & 7.47 & 0.0195 \\
\hline & $\mathrm{D}: N$ & 1.6384 & 1 & 1.6384 & 0.57 & 0.4659 \\
\hline & Error total & 31.5829 & 11 & 2.87118 & - & - \\
\hline & Total(corr.) & 433.312 & 15 & - & - & - \\
\hline \multirow{6}{*}{$R=1000 \Omega$} & $\mathrm{A}: I_{\mathrm{S}}$ & 102.718 & 1 & 102.718 & 41.39 & 0.0000 \\
\hline & $\bar{B}: C_{j}$ & 216.531 & 1 & 216.531 & 87.25 & 0.0000 \\
\hline & $\mathrm{C}: R_{\mathrm{S}}$ & 9.51722 & 1 & 9.51722 & 3.83 & 0.0760 \\
\hline & $\mathrm{D}: N$ & 1.13422 & 1 & 1.13422 & 0.46 & 0.5130 \\
\hline & Error total & 27.3005 & 11 & 2.48186 & - & - \\
\hline & Total(corr.) & 357.201 & 15 & - & - & - \\
\hline
\end{tabular}

Tab. 6. ANOVA of the rectifier of the voltage doubler.

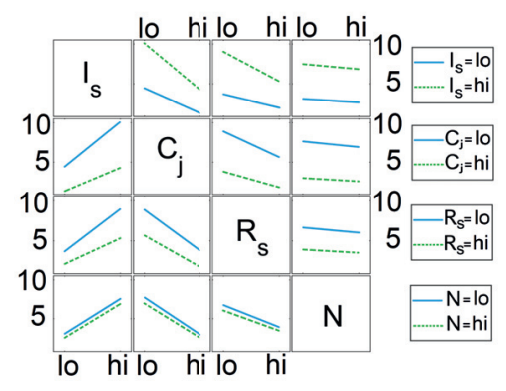

(a)

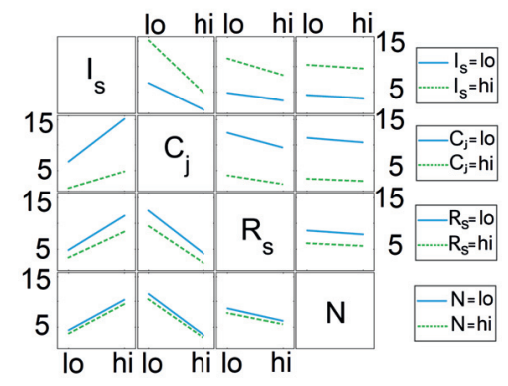

(b)

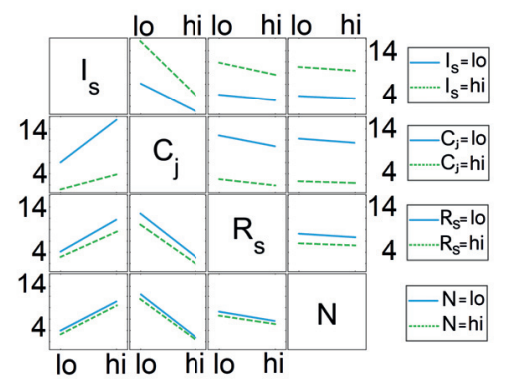

(c)

Fig. 6. Influence of the interaction between the main effects in the conversion efficiency of the rectifier of voltage doubler, when the load resistance was $100 \Omega(\mathrm{a}), 500 \Omega(\mathrm{b})$, and $1000 \Omega(\mathrm{c})$.

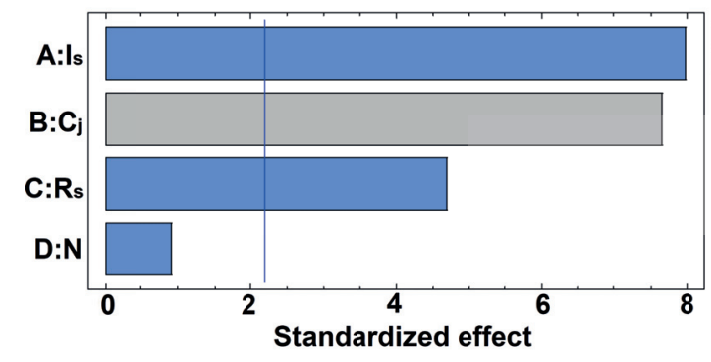

(a)

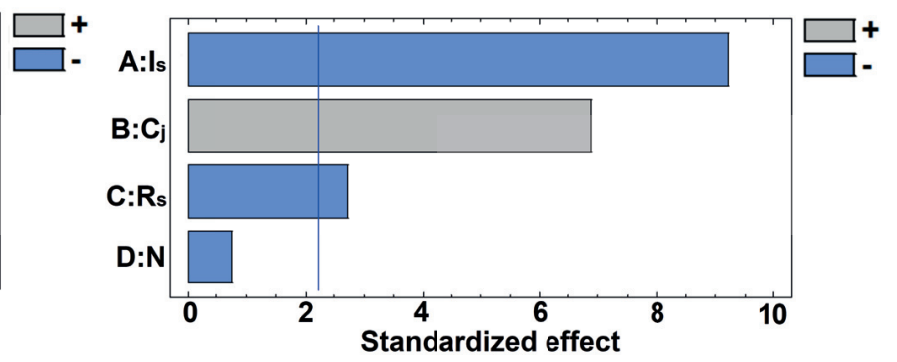

(b)

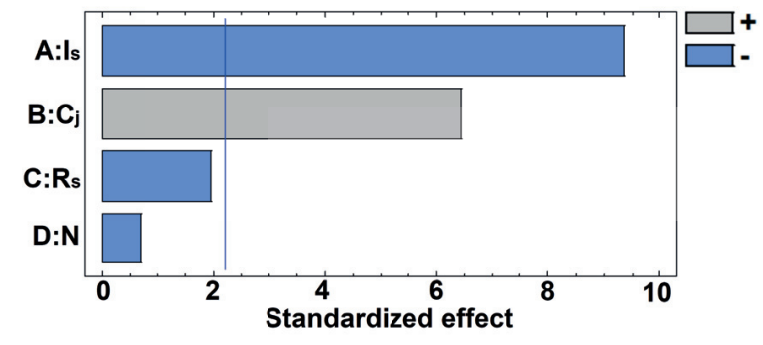

(c)

Fig. 7. Diagram of standardized Pareto for the efficiency of the rectifier of voltage doubler, when the load resistance was $100 \Omega$ (a), $500 \Omega$ (b), and $1000 \Omega$ (c). 


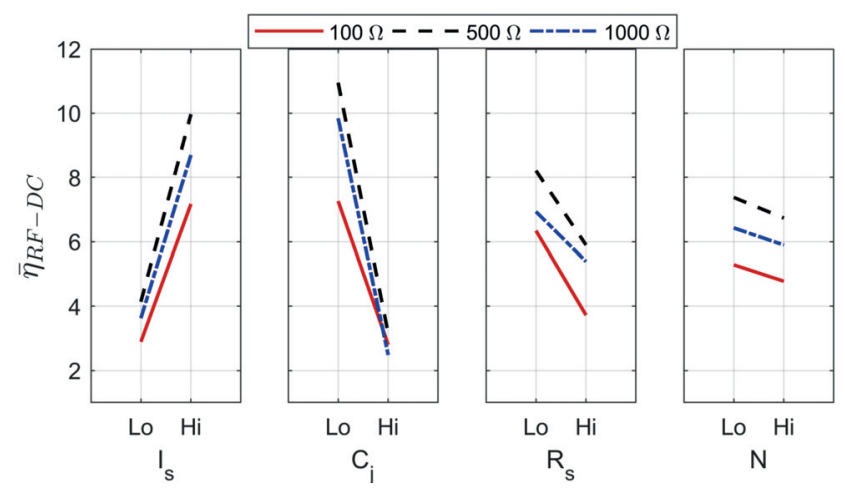

Fig. 8. Influence of the main effects in the conversion efficiency of the rectifier of voltage doubler.

Additionally, in the ANOVA is important to determine the influence of the interaction between the factors (Fig. 6). For this rectifier, the resultant lines did not converge at any point in the evaluation space. Hence, there is no influence of the interaction between parameters over the RF-DC conversion efficiency in all the values of load resistance, as it happened with the single diode rectifier.

\section{Conclusions}

The main contribution of this work is a set of selection criteria for diodes that enables to obtain the best RF-DC conversion efficiency in the rectifiers of multiband rectennas for frequencies from 1.7 to $3.7 \mathrm{GHz}$. These criteria are proposed considering the circuit topologies more employed in recent years, i.e. the single diode and the voltage doubler. Such criteria are not established in current literature, and recent research works have selected the diode family with basis on the availability or the preference of the authors. In order to accomplish the objective, an ANOVA test was carried out in this research considering four different diode parameters to determine their influence on the RF-DC conversion efficiency of multiband rectifiers employed in the design of rectennas in frequencies from 1.7 to $3.7 \mathrm{GHz}$. The ANOVA test of the four main parameters of the diode: the emission coefficient, the series resistance, the junction capacitance, and the saturation current allowed to establish selection criteria for diodes or diode families.

According to the results obtained, it is established that for attaining high values of RF-DC conversion efficiency in a multiband rectifier it is necessary that the diode has a high level of saturation current and a low level of junction capacitance, mainly. Also, the diode must have low levels of series resistance and emission coefficient. These criteria were similar for the rectifier with a single diode and the voltage doubler.

Between the diode families, which have been employed in literature, there was not a particular family that accomplishes these criteria. Therefore, it permits the development of future research focused on designing diodes with these characteristics. Nevertheless, if it is necessary to select a commercial diode family, the selection must be made through a trade-off between the parameters.

In the cases studied in this research, the diode family that complies with this trade-off is the SMS-763x, in its single diode configuration and series pair for the voltage doubler, because these diodes have the highest values of saturation current, the lowest emission coefficients, and low junction capacitances. Although their series resistances are high, this parameter did not present a dominant influence in the RF-DC conversion efficiency.

Finally, future works can be conducted in the evaluation of the influence of the diode parameters in other circuit topologies, which are not the most used in recent years. Additionally, it is possible to perform this analysis for higher frequency ranges, for example in satellite communications on the range from 11 to $14 \mathrm{GHz}$.

\section{References}

[1] CONTRERAS, A., URDANETA, M. Rectennas for energy harvesting from RF communication systems: A review (in Spanish). Revista Tecnica de la Facultad de Ingenieria Universidad del Zulia, 2020, vol. 43, no. 2, p. 98-109. DOI: 10.22209/rt.v43n2a06

[2] CANSIZ, M., ALTINEL, D., KARABULUT, K. G. Efficiency in RF energy harvesting systems: A comprehensive review. Energy, 2019, vol. 174, p. 292-309. DOI: 10.1016/j.energy.2019.02.100

[3] DIVAKARAN, S., KRISNA, D. D., NASIMUDDIN, N. RF energy harvesting systems: An overview and design issues. International Journal of RF and Microwave Computer-Aided Engineering, 2018, vol. 29, p. 1-15. DOI: $10.1002 /$ mmce. 21633

[4] VISSER, H. Indoor wireless RF energy transfer for powering wireless sensors. Radioengineering, 2012, vol. 21, no. 4, p. 963-973. ISSN: $1210-2512$

[5] SURENDER, D., KHAN, T., TALUKDAR, F., et al. Key components of rectenna system: A Comprehensive Survey. IETE Journal of Research, 2020, p. 1-28. DOI: 10.1080/03772063.2020.1761268

[6] SHAHABUDDIN, A., SHALU, P., AKTER, N. Optimized process design of RF energy harvesting circuit for low power devices. International Journal of Applied Engineering Research, 2018, vol. 13, no. 2, p. 849-854. ISSN: 0973-4562

[7] SONG, C., HUANG, Y., ZHOU, J., et al. Matching network elimination in broadband rectennas for high-efficiency wireless power transfer and energy harvesting. IEEE Transactions on Antennas and Propagation, 2017, vol. 64, no. 4, p. 2057-2062. DOI: 10.1109/TAP.2017.2670359

[8] ROEHR, W. Rectifier Applications Handbook. 1st ed. Denver (USA): ON Semiconductor, 2001.

[9] RANDA, M., MAHA, A., MENNA, A., et al. A foldable textile-based broadband archimedean spiral rectenna for RF energy harvesting. In 16th Mediterranean Microwave Symposium (MMS). Abu Dhabi (UAE), 2016, p. 1-4. DOI: 10.1109/MMS.2016.7803872

[10] SINGH, N., KANAUJIA, B., BEG, M., et al. A dual polarized multiband rectenna for RF energy harvesting. AEU - International Journal of Electronics and Communications, 2018, vol. 93, no. 2018, p. 123-131. DOI: 10.1016/j.aeue.2018.06.020 
[11] INDUMATHI, G., KARTHIKA, K. Rectenna design for RF energy harvesting in wireless sensor networks. In 2015 IEEE International Conference on Electrical, Computer and Communication Technologies (ICECCT). Coimbatore (India), 2015, p. 9-12. DOI: 10.1109/ICECCT.2015.7226171

[12] AGRAWAL, S., PARIHAR, M., KONDEKAR, P. Broadband rectenna for radio frequency energy harvesting application broadband rectenna for radio frequency energy harvesting application. IETE Journal of Research, 2017, vol. 64, no. 3, p. 347-353. DOI: $10.1080 / 03772063.2017 .1356755$

[13] SINGH, B., GHOSH, S., CHAKRABARTI, S. Design optimization and implementation of multiband rectenna for efficient radio frequency energy harvesting. In 2017 IEEE International Conference on Industrial and Information Systems (ICIIS). Peradeniya (Sri Lanka), 2017, p. 1-6. DOI: 10.1109/ICIINFS.2017.8300355

[14] PALAZZI, V., HESTER, J., BITO, J., et al. A novel ultralightweight multiband rectenna on paper for RF energy harvesting in the next generation LTE bands. IEEE Transactions on Microwave Theory and Techniques , 2018, vol. 66, no. 1, p. 366-379. DOI: 10.1109/TMTT.2017.2721399

[15] AGRAWAL, S., PARIHAR, M., KONDEKAR, P. A quad-band antenna for multi-band radio frequency energy harvesting circuit. $A E U$ - International Journal of Electronics and Communications, 2018, vol. 85, p. 99-107. DOI: 10.1016/j.aeue.2017.12.035

[16] NARESH, B., SINGH, V., BHARGAVI, V. Dual band RF energy harvester for wearable electronic technology. In 2017 Third International Conference on Advances in Electrical, Electronics, Information, Communication and Bio-Informatics (AEEICB). Chennai (India), 2017, no. 1, p. 3-6. DOI: 10.1109/AEEICB.2017.7972428

[17] TISSIER, J., LATRACH, M. Broadband rectenna for ambient RF energy harvesting applications. In 2017 XXXIInd General Assembly and Scientific Symposium of the International Union of Radio Science (URSI GASS). Montreal (Canada), 2017, p. 2-4. DOI: $10.23919 /$ URSIGASS.2017.8105356

[18] CHEN, Y., CHIU, C. Characterization of the lossyness of matching networks for RF energy-harvesting rectennas. In 11th European Conference on Antennas and Propagation (EUCAP). Paris (France), 2017, p. 2053-2056. DOI: 10.23919/EuCAP.2017.7928097

[19] ZAINUDDIN, N., ZAKARIA, Z., HUSAIN, M., et al. Design of wideband antenna for RF energy harvesting system. In 3rd International Conference on Instrumentation, Соттиnications, Information Technology, and Biomedical Engineering (ICICI-BME). Bandung (Indonesia), 2013, p. 162-166. DOI: 10.1109/ICICI-BME.2013.6698485

[20] IBRAHIM, R., VOYER, D., ZOGHBI, M., et al. Novel design for a rectenna to collect pulse waves at $2.4 \mathrm{GHz}$. IEEE Transactions on Microwave Theory and Techniques, 2018, vol. 66, no. 1, p. 357-365. DOI: 10.1109/TMTT.2017.2749579

[21] KHEMAR, A., KACHA, A., TAKHEDMIT, H., et al. Design and experiments of a dual-band rectenna for ambient RF energy harvesting in urban environments. IET Microwaves, Antennas \& Propagation, 2018, vol. 12, no. 1, p. 49-55. DOI: 10.1049/iet-map.2016.1040

[22] SONG, C., HUANG, Y., ZHOU, J., et al. Improved ultra-wideband rectennas using hybrid resistance compression technique. IEEE Transactions on Antennas and Propagation, 2017, vol. 65, no. 4, p. 2057-2062. DOI: 10.1109/TAP.2017.2670359

[23] SONG, S., SU, M., LIU, Y., et al. A novel broadband rectenna for energy harvesting. In International Symposium on Antennas and Propagation (ISAP). Okinawa (Japan), 2016, no. 3, p. 1082-1083. ISBN: 978-4-88552-313-7
[24] HO, D., KHARRAT, I., VOUNG, V., et al. Dual-band rectenna for ambient RF energy harvesting at GSM $900 \mathrm{MHz}$ and 1800 MHz. In IEEE International Conference on Sustainable Energy Technologies (ICSET) Dual-Band. Hanoi (Vietnam), 2016, p. 306-310. DOI: 10.1109/ICSET.2016.7811800

[25] SHEN, S., CHIU, C., MURCH, R. A dual-port triple-band 1probe microstrip patch rectenna for ambient RF energy harvesting. IEEE Antennas and Wireless Propagation Letters, 2017, vol. 16, p. 3071-3074. DOI: 10.1109/LAWP.2017.2761397

[26] ZENG, M., LI, Z., ANDRENKO, et al. A compact dual-band rectenna for gsm900 and gsm1800 energy harvesting. International Journal of Antennas and Propagation, 2018, vol. 2018, p. 1-10. DOI: $10.1155 / 2018 / 4781465$

[27] AVAGO. HSMS-282x Surface Mount RF Schottky Barrier Diodes. 15 pages. [Online] Cited 2020-07-03. Available at: https://datasheetspdf.com/pdf/963454/AVAGO/HSMS-2822/1

[28] AGILENT. HSMS-285x Series Surface Mount Zero Bias Schottky Detector Diodes. 13 pages. [Online] Cited 2020-07-04. Available at: https://datasheet.octopart.com/HSMS-2850-BLK-Avagodatasheet-46446.pdf

[29] H. PACKARD. HSMS-2860 Series Surface Mount Microwave Schottky Detector Diodes. 6 pages. [Online] Cited 2020-07-05. Available at: https://datasheetspdf.com/pdf/815268/HP/HSMS-2860/1

[30] SKYWORKS. Surface Mount Mixer and Detector Schottky Diodes. 10 pages. [Online] Cited 2020-07-05. Available at: https://www.rfmw.com/datasheets/skyworks/200041i.pdf

[31] MONTGOMERY, D. Design and Analysis of Experiments (in Spanish). 2nd ed. Mexico (Mexico): Limusa, Wiley, 2004. ISBN: 9681861566

[32] SAUTER, M. From GSM to LTE-Advanced Pro and 5G. 3rd ed. New Jersey (US): John Wiley \& Sons Ltd, 2017. ISBN: 9781119346906

[33] COLLADO, A., DASKALAKIS, S., NIOTAKI, K., et al. Rectifier design challenges for RF wireless power transfer and energy harvesting systems. Radioengineering, 2017, vol. 26, no. 2, p. 411-417. DOI: $10.13164 /$ re.2017.0411

\section{About the Authors ...}

Andry CONTRERAS was born in Maracaibo, Venezuela. He received his degree in Electrical Engineering and his M.Sc. in Applied Sciences. Physics from Universidad del Zulia in 2009 and 2012, respectively. He is currently pursuing his Ph.D. in Engineering from Universidad del Zulia, Venezuela. He did a research internship at Universidad de la República, Uruguay, in 2018. Since February 2010 he is working as an Assistant Professor in the Department of Circuits and Communications in the Faculty of Engineering, Universidad del Zulia. His research interests include printed antennas, components in the microwave frequencies, rectennas, wireless power transmission, RF energy harvesting and optimization.

Maryory URDANETA was born in Maracaibo - Venezuela. She received her B.Sc. in Electrical Engineering in 2003 at Universidad del Zulia. In 2010 she received the Fulbright scholarship to complete her Ph.D. degree in Electrical Engineering at University of Central Florida in Orlando - USA, which was finished in 2015. Her research interests include antennas, bioelectromagnetics, RF and MW fields. 